\title{
Yetiştirme sıklığının Toros sediri fidanlarının dikim başarısına etkisi
}

\author{
The effect of seedbed density on the field performance of Taurus cedar seedlings
}

\author{
Şükrü Teoman GÜNER ${ }^{1}$ \\ Dilek GÜNER ${ }^{2}$ \\ Uğur ŞAHİN²
}

\begin{abstract}
${ }^{1}$ Bartın Üniversitesi, Ulus Meslek Yüksekokulu, Ormancılık Bölümü, Ulus/Bartın

${ }^{2}$ Orman Toprak ve Ekoloji Araştırmaları Enstitüsü Müdürlüğü, Eskişehir
\end{abstract}

Sorumlu yazar (Corresponding author) Şükrü Teoman GÜNER stguner@gmail.com

Geliş tarihi (Received)

27.12.2020

Kabul Tarihi (Accepted) 22.02.2021

Sorumlu editör (Corresponding editor) Fatma FEYZİOĞLU

fatmafeyzioglu@ogm.gov.tr

Atıf (To cite this article): Güner, S, Güner, D, Sahin, U . (2021). Yetiștirme sıklığının Toros sedir fidanlarının dikim başarısına etkisi . Ormancılık Araştırma Dergisi , 8 (2), 117-124 DOI: https://doi.org/10.17568/ogmoad.847876

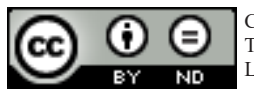

Creative Commons Atıf Cïn Atif Uüretilemez 4.0 Uluslarar
Lisansı ile lisanslanmıștır.

\section{Öz}

Çalışma, yetiştirme sıklığının Toros sediri (Cedrus libani A. Rich.) fidanlarının dikim başarısına etkisini ortaya koymak amacıyla yapılmıştır. Araştırmada, Isparta-Kapıdağ orijinli tohumlar, Eskişehir Orman Fidanlığında $15 \mathrm{~cm}$ aralıklarla oluşturulan 7 ekim çizgisine sahip yastıklara 2015 yılında ekilmiştir. 1,5 (kontrol); 2,5; 5,0; 7,5 ve $10,0 \mathrm{~cm}$ mesafe ile yetiştirilen $2+0$ yaşlı çıplak köklü fidanlar Eskişehir-Mihalıççık yöresindeki yarı kurak ve yarı nemli iklim özelliklerine sahip iki sahaya $3 \times 2 \mathrm{~m}$ aralık-mesafe ile dikilmiştir. Dikimi takiben 1., 2. ve 3 . vejetasyon dönemi sonunda her iki deneme alanında fidan yaşama yüzdesi tespit edilirken, sadece yarı kurak iklim özelliklerine sahip deneme alanında fidan boyu ve fidan çapı ölçümleri yapılmış, nispi çap ve boy artımları hesaplanmıştır. Her iki alanda farklı sıklıkta yetiştirilen fidanların arazideki yaşama yüzdeleri arasında anlamlı bir farklılık belirlenememiştir. Ancak, yarı kurak iklim özelliklerine sahip deneme alanında fidan boyu ve çap gelişimi ile nispi boy ve çap artımları bakımından farklı sıklıkta yetiştirilen fidanlar arasında önemli farklılıklar bulunmuştur. Elde edilen veriler, fidanlıklarda birim alandan dikime elverişli fazla sayıda fidan üretme gerekliliği ve 3 . vejetasyon dönemi sonundaki boy farklar1 dikkate alındığında, yarı kurak alan ağaçlandırmalarında, fidanlıkta $15,0 \times 2,5 \mathrm{~cm}$ aralık-mesafeyle $\left(232 \mathrm{fidan} / \mathrm{m}^{2}\right)$ fidan yetiştirmenin uygun olacağ 1 söylenebilir.

Anahtar kelimeler: Cedrus libani, yetiştirme sıklığı, arazi başarısı

\section{Abstract}

This study was carried out to find out the effect of seedling density on the planting success of Taurus cedar (Cedrus libani A. Rich.) seedlings. The seeds, collected from Isparta-Kapidag provenance, were sown in the seedbeds with $15 \mathrm{~cm}$ spacing of 7 lines in Eskisehir Forest Nursery in 2015. Two-year-old $(2+0)$ bareroot seedlings grown with 1.5 (control), 2.5, 5.0, 7.5, $10.0 \mathrm{~cm}$ spacings were planted with $3 \times 2 \mathrm{~m}$ spacing in two areas with climates of semi-arid and semi-humid in Eskisehir-Mihaliccik region. Following planting, survival percentage was determined at the end of the first, the second, and the third vegetation periods in the two areas, while the seedling height and diameter were measured and their relative growths were calculated only in the semi-arid area. No significant difference was determined among the survival percentage of the seedlings grown at different densities at both sites. However, the growth of seedling height and diameter and the relative increments of height and diameter were significantly different among the seedlings grown at different densities in the semiarid site. Considering the data obtained, the necessity of producing more seedlings suitable for planting per unit area in nurseries, and the height differences at the end of the $3^{\text {rd }}$ vegetation period, growing of Taurus cedar seedlings with $15.0 \times 2.5 \mathrm{~cm}$ spacings $(232$ seedlings per $\mathrm{m}^{2}$ ) in the nurseries for semi-arid regions can be suggested.

Key words: Cedrus libani, seed bed density, field performance 


\section{Giriş}

Adaptasyon yeteneği ve fidan yaşama yüzdesi yüksek olan Toros sediri (Cedrus libani A. Rich.), farklı ekolojik koşullara sahip olan doğal yayılıș alanı dışındaki ağaçlandırmalarda da sıklıkla kullanılmaktadır. Türkiye'deki ağaçlandırmalarda k1zılçam (Pinus brutia Ten.) ve karaçam (Pinus nigra Arn.)'dan sonra en fazla kullanılan tür Toros sediridir (Boydak ve Çalıkoğlu, 2008).

Türkiye'de 1992-2014 döneminde yılda ortalama 35.850 hektar ağaçlandırma yapılmış olup, bu alanın yaklaşık \%30’u (10.620 ha) yarı kurak iklim özelliklerine sahip alanlarda bulunmaktadır (ÇEM, 2015). Toros sediri İç Anadolu Bölgesi’ndeki ağaçlandırmalarda sıklıkla kullanılmaktadır. Araştırmanın yapıldığı Eskişehir Orman Fidanlığı'nda yılda ortalama 4,5 milyon adet çıplak köklü Toros sediri fidanı üretilmektedir. Dolayısıyla Toros sediri fidanı üretimi ile bu fidanların farklı yetişme ortamlarındaki ağaçlandırma başarılarının değerlendirilmesi konusunda araştırmalara ihtiyaç bulunmaktadır (Güner ve ark., 2018).

Her türlü plantasyon çalışmasında, yüksek tutma başarısı gösteren ve ilk yıllarda yaşamını aktif bir biçimde sürdürerek çok iyi büyüme yapabilen ve aynı zamanda bu avantajlarla ekonomik dengede olan fidan kalitelidir (Tolay, 1983). Orman kurma çalışmasında bakım süresi ne kadar kısaltılabilmişse o denli başarılı olunmuş demektir. $\mathrm{Bu}$ ise dikilen fidanların yaşama oranı yanında sıklık çağına ulaşma süresinin kısalığına bağlıdır. Sıklık çağına ulaşma süresi fidanın çap ve boy artımına; başka bir söyleyişle kaliteli fidan kullanımına göre değişmektedir. Fidan kalitesi üzerinde etkili olan etmenlerden birisi ise ekim yastıklarında sıklığın düzenlenmesidir (Yahyaoğlu ve Genç, 2007). Yapılan araştırmalarda yetiştirme sıklığının fidan morfolojik ve fizyolojik özellikleri üzerinde etkili olduğu belirlenmiştir (Çiçek ve ark., 2007; Semerci ve ark., 2008; Güner ve ark., 2008; Deligöz, 2012; Yücedağ ve Gailing, 2012; Güner ve ark., 2016; Alım ve Kavgac1, 2017).

Toros sedirinde yetiştirme sıklığının fidan özelliklerine etkisi konusunda, Eğirdir Orman Fidanl1ğı'nda (Isparta) Isparta-Kapıdağ orijininde (Çatal, 2002), Hazar Orman Fidanlığ'ında (Elazığ) Kahramanmaraş-Suçatı orijininde (Kayadibi, 2011), Eskişehir Orman Fidanlığı'nda Konya-Bademli, Mersin-Erdemli ve Isparta-Belceğiz orijinlerinde (Güner ve ark., 2016) çalışmalar yapılmıştır. Bu çalışma ise Eskişehir Orman Fidanlığı koşullarında Isparta-Kapıdağ orijinli tohumlarla yapılması ve arazi denemesinin olması bakımından diğer çalışmalardan ayrılmaktadır.
$\mathrm{Bu}$ araştırmanın ilk aşamasında, fidan kalitesi üzerinde etkili olan yetiştirme sıklığının, 2+0 yaş11 çıplak köklü Toros sediri fidanlarının (Kapıdağ orijinli) önemli morfolojik özellikleri ve beslenme durumu üzerine olan etkileri ortaya konulmuştur (Güner ve ark., 2018). İkinci aşama olan bu çalışmada ise yetiştirme sıklığının Toros sediri fidanlarının dikim başarısı üzerindeki etkisi araştırılmıştır.

\section{Materyal ve Yöntem}

\subsection{Materyal}

Araştırmada, Isparta-Kapıdağ orijinli Toros sediri tohum meşceresinden (TM 239) toplanan tohumlar kullanılmıştır. 3805'23' kuzey enlemi ile 30²'20" doğu boylamı arasında yer alan meşcerenin ortalama yükseltisi $1600 \mathrm{~m}$ ve bakısı kuzeydir (Güner ve ark., 2018).

Çalışmanın fidanlık aşaması $804 \mathrm{~m}$ yükseltide, 3943'18' '39 44'48' kuzey enlemleri ile $30^{\circ} 25^{\prime} 06^{\prime}$ '-30²6'43' doğu boylamları arasında bulunan Eskişehir Orman Fidanlığı'nda gerçekleştirilmiştir. Eskişehir soğuk-yarı karasal iklim tipine sahiptir. Eskişehir Meteoroloji İstasyonunun 1975-2006 yıllarını kapsayan verilerine göre; yıllık ortalama sicaklık $10,6^{\circ} \mathrm{C}$ ve yıllık ortalama yağ 1 ş miktar1 307,2 mm dir. Büyüme süresi yaklaşık 240 gündür. Thornthwaite metoduna göre iklim tipi yarı kuraktır. Sıcaklık ilişkileri bakımından orta sıcaklıklar hâkimdir. Su açığı 305,5 mm olup, haziran-ekim ayları arasındaki beş aylık dönemi kapsamaktadır. Denemenin kurulduğu yastığın toprağ1 kil, kapatma materyali ise balçıklı kum türündedir (Güner ve ark., 2018).

Çalışmanın arazi denemesi Eskişehir ili, Mihalıççık ilçesi sınırlarında yer alan yarı kurak (Sazak) ve yarı nemli (Diközü) iklim özelliklerine sahip olan iki sahada kurulmuştur. Sazak sahasının (3947'31''K, 31³4'20'’D) yükseltisi $890 \mathrm{~m}$, bakısı güney ve eğimi \%8'dir. Sazak sahasını en iyi temsil edeceği düşünülen Sivrihisar Meteoroloji İstasyonunun (1.065 m) 1990-2020 yıllarını kapsayan verilerine göre; yıllık ortalama sıcaklık 12,5 ${ }^{\circ} \mathrm{C}$, yıllık ortalama yüksek sıcaklık $17,6{ }^{\circ} \mathrm{C}$ ve yıllık ortalama toplam yağış miktarı ise $413,5 \mathrm{~mm}$ 'dir (MGM, 2021). Buna göre Sazak sahasının Erinç yağış etkenliği indisi değeri (Im) 17,2 olup, yarı kurak iklim tipinde yer almaktadır (Özyuvacı, 1999). Diközü sahasının (3950'25' K, 31²9'40' D) yükseltisi 1.260 m, bakısı doğu ve eğimi \% 2'dir. Diközü sahasına yakın bir mesafede bulunan Mihalıççık Meteoroloji İstasyonunun (1.325 m) 2013-2020 yıllarını kapsayan 8 yıllık verilerine göre; yıllık ortalama sicaklık $9,6^{\circ} \mathrm{C}$, y1llık ortalama yüksek sıcaklık $14,7^{\circ} \mathrm{C}$, yıllık ortalama toplam yağış mik- 
tar1 ise 456,4 mm'dir (MGM, 2021). Bu verilerle denemenin kurulduğu sahanın Erinç yağış etkenliği indisi değeri (Im) 28,1 olup yarı nemli iklim tipinde kalmaktadır (Özyuvac1, 1999).

Deneme alanlarına ait toprak özelliklerini belirlemek amacıyla her deneme alanında bir adet toprak çukuru açılmış ve derinlik kademelerine göre bozulmuş toprak örnekleri alınmıştır. Araziden alınan toprak örneklerinin bazı fiziksel ve kimyasal özellikleri Orman Toprak ve Ekoloji Araştırmalar1 Enstitüsü Müdürlügü laboratuvarlarında analiz edilmiştir. Analiz sonuçlarına göre Sazak sahası orta, Diközü sahası ise ince tekstürlüdür. Her iki deneme alanındaki topraklar alkalen reaksiyonlu, kireçli ve tuzsuzdur. Yine her iki deneme alanında toprakların organik madde ve toplam azot içerikleri 0-20 cm derinlik kademesinde orta, diğer derinlik kademelerinde ise düşük düzeydedir (Tablo 1).

Tablo 1. Deneme alanlarına ait toprak özellikleri

Table 1. Soil properties of the plots

\begin{tabular}{ccccccccccc}
\hline \multirow{2}{*}{ Saha } & $\begin{array}{c}\text { Derinlik } \\
(\mathrm{cm})\end{array}$ & $\begin{array}{c}\text { ITM } \\
(\mathrm{g} / \mathrm{l})\end{array}$ & $\begin{array}{c}\text { Kum } \\
(\%)\end{array}$ & $\begin{array}{c}\text { Toz } \\
(\%)\end{array}$ & $\begin{array}{c}\text { Kil } \\
(\%)\end{array}$ & TT & $\mathrm{pH}$ & $\begin{array}{c}\text { Kt } \\
(\%)\end{array}$ & $\begin{array}{c}\text { OM } \\
(\%)\end{array}$ & $\begin{array}{c}\text { EC } \\
(\mathrm{mS} / \mathrm{cm})\end{array}$ \\
\hline \multirow{5}{*}{ Sazak } & $0-20$ & 985 & 62,78 & 20,68 & 16,54 & $\mathrm{KuBa}$ & 8,20 & 4,81 & 1,51 & 0,14 \\
& $20-40$ & 974 & 58,49 & 18,68 & 22,83 & KuKiBa & 8,34 & 13,33 & 0,91 & 0,12 \\
& $40-60$ & 1166 & 52,13 & 20,81 & 27,06 & KuKiBa & 8,39 & 17,43 & 0,69 & 0,12 \\
& $60-80$ & 1236 & 45,81 & 22,93 & 31,26 & KuKiBa & 8,57 & 21,32 & 0,39 & 0,13 \\
& $80-100$ & 1267 & 58,72 & 18,58 & 22,71 & KuKiBa & 8,60 & 17,48 & 0,40 & 0,13 \\
\hline \multirow{5}{*}{ Diközüu } & $0-20$ & 968 & 36,35 & 19,10 & 44,56 & Ki & 7,69 & 0,33 & 3,60 & 0,17 \\
& $20-40$ & 1039 & 49,94 & 20,86 & 29,20 & KuKiBa & 8,03 & 45,01 & 0,99 & 0,13 \\
& $40-60$ & 1075 & 43,59 & 22,98 & 33,43 & KiBa & 8,11 & 29,53 & 0,83 & 0,13 \\
& $60-80$ & 964 & 47,66 & 23,03 & 29,31 & KuKiBa & 8,17 & 24,72 & 0,66 & 0,14 \\
& $80-100$ & 877 & 42,88 & 23,27 & 33,85 & KiBa & 8,11 & 12,38 & 0,57 & 0,13 \\
\hline \multirow{5}{*}{ Sazak } & & $\mathrm{N}$ & $\mathrm{P}$ & $\mathrm{K}$ & $\mathrm{Na}$ & $\mathrm{Ca}$ & $\mathrm{Mg}$ & $\mathrm{TK}$ & $\mathrm{SN}$ & YR \\
& $0-20$ & 0,11 & 6,2 & 330 & 9 & 3435 & 620 & 42,84 & 12,83 & 30,01 \\
& $20-40$ & 0,07 & 3,7 & 76 & 16 & 4050 & 732 & 44,57 & 15,93 & 28,64 \\
& $40-60$ & 0,05 & 3,7 & 73 & 22 & 3721 & 859 & 45,83 & 17,06 & 28,77 \\
& $60-80$ & 0,04 & 2,6 & 65 & 33 & 3074 & 977 & 47,35 & 17,44 & 29,91 \\
& $80-100$ & 0,04 & 2,6 & 59 & 35 & 3256 & 962 & 39,64 & 14,04 & 25,60 \\
\hline
\end{tabular}

ITTM: ince toprak miktarı $(\varnothing<2 \mathrm{~mm}), \mathrm{Kt}$ : toplam kireç, OM: organik madde, EC: elektriki iletkenlik, TK: tarla kapasitesi, SN: solma noktası, YR: yarayışlı rutubet, TT: toprak türü, Ku: kum, Ki: kil, Ba: balçık

\subsection{Yöntem}

Eskişehir Orman Fidanlık Müdürlüğü tarafından 2014 yılı sonbaharında (ekim-kasım) Isparta-Kapıdağ orijinli tohum meşceresinden toplanan Toros sediri kozalakları kışın (aralık-ocak) fidanlıkta açılmış ve elde edilen tohumlar 03 Mart 2015 tarihinde $120 \mathrm{~cm}$ eninde ve 7 ekim çizgisine sahip (ekim çizgileri arası $15 \mathrm{~cm}$ ) yastıklara $\mathrm{m}^{2}$ 'ye 220 g tohum olacak şekilde ekilmiştir. Denemede kullanılan tohumların, Orman Ağaçları ve Tohumları
Islah Araştırma Enstitüsü Müdürlüğü tarafından yapılan kalite kontrolünde; temizliği \%82, 1000 tane ağırlığ 84,4 g, nem içeriği \%34,5, çimlenme h1z1 $\% 22$ ve çimlenme yüzdesi $\% 52$ olarak tespit edilmiştir. Çimlenmelerin tamamlanmasından yaklaşı bir ay sonra (02 Haziran 2015), fidanlar arasında 2,5 cm (232 fidan $\left./ \mathrm{m}^{2}\right) ; 5,0 \mathrm{~cm}$ (116 fidan/ $\left.\mathrm{m}^{2}\right) ; 7,5 \mathrm{~cm}$ (77 fidan $/ \mathrm{m}^{2}$ ) ve $10,0 \mathrm{~cm}$ (58 fidan/ $\mathrm{m}^{2}$ ) mesafe olacak şekilde dört düzeyde seyreltme yapılmıştır. İşlem parselleri arasında $30 \mathrm{~cm}$ genişliğinde tampon zonlar bırakılmıştır. İşlemlerin 
yastıklara dağıtımında, "rastlantı parselleri deneme deseni" kullanılmış ve deneme 3 yinelemeli olarak kurulmuştur. Ayrica, yine tesadüfî olarak belirlenen üç kontrol parseli de denemeye ilave edilmiştir. Kontrol parsellerinde herhangi bir seyreltme işlemi uygulanmamış olup, fidanlar arasındaki mesafe 1,5 $\mathrm{cm}$ (387 fidan $/ \mathrm{m}^{2}$ ) olarak belirlenmiştir. Deneme fidanlıkta aplike edildikten sonra, iki vejetasyon dönemi boyunca rutin ot alma, sulama, gübreleme ve kök kesimi faaliyetleri gerçekleştirilmiştir. İkinci vejetasyon dönemi sonunda (27.02.2017) 2+0 yaşl1 fidanlar alttan kök kesimini takiben ekim yastıklarından sökülmüştür. Alttan kök kesimi, köklerin yüksekten kesilmesi riski göz önünde bulundurularak, denemenin zarar görmemesi adına, yaklaşık 30 $\mathrm{cm}$ derinlikte yapılmıştır. Daha sonra fidan kökleri kök boğazından itibaren $20 \mathrm{~cm}$ uzunlukta kesilmiştir. Araştırmada yastığın ortasında kalan beş sıradaki fidanlar kullanılmış, yastığın her iki tarafında kenarlara gelen birer sira fidan tecrit zonu olarak bırakılmıştır (Güner ve ark., 2018).

Farklı sıklık derecelerinde yetiştirilen fidanların yarı kurak (Sazak) ve yarı nemli (Diközü) iklim özellikleri taşıyan deneme alanlarına dikimi 28.02.2017 tarihinde gerçekleştirilmiştir. Arazi denemesinde yöntem olarak "rastlantı parselleri deneme deseni" uygulanmış ve deneme 3 yinelemeli olarak kurulmuştur. Her bir parsele fidanlıkta farklı sıklıklarda yetiştirilmiş ve bu sıklıkları temsilen rasgele seçilmiş 30 fidan dikilmiştir. Dikimlerdeki aralık-mesafe $3 \times 2$ m olarak uygulanmıştır.

Her iki deneme alanında dikimi takiben 3 yıl boyunca bakım çalışmaları ve gözlemler sürdürülmüştür. Yarı nemli (Diközü) iklim özelliklerine sahip olan sahaya hem 2018 hem de 2019 yılı ilkbaharında küçükbaş hayvan sokulması sonucunda deneme alanına dikilen fidanların neredeyse tamamında tepe sürgünlerinin yenildiği tespit edilmiştir. Bu durum, otlatmadan zarar gören fidanlarda

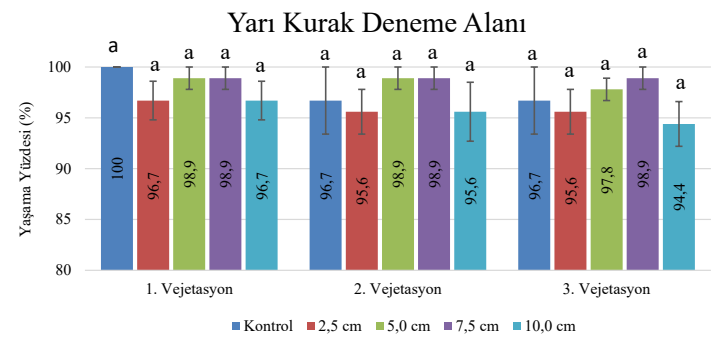

yan sürgünlerden birinin tepe sürgünü konumuna geçmesine, dolayısıyla fidanlarda büyüme kayıplarına sebep olmuştur. Bu yüzden, yarı nemli iklim özelliklerine sahip olan sahanın sadece 1., 2. ve 3. vejetasyon dönemi sonunda belirlenen fidan yaşama yüzdesi değerleri kullanılmış, çap ve boy gelişimleri ile nispi artımları değerlendirme dışı b1rakılmıştır. Yarı kurak (Sazak) iklim özelliklerine sahip olan deneme alanında 1., 2. ve 3. vejetasyon dönemi sonunda fidan yaşama yüzdeleri yanında çap ve boy ölçümleri yapılmış, ayrıca nispi çap ve boy artımları da hesaplanmıştır. Nispi çap ve boy artımlarının hesabında aşağıdaki formül (Yahyaoğlu ve Genç, 2007) kullanılmıştır:

$N A=\left[1 / X_{0}\right] \times\left[\left(X_{i}-X_{0}\right) /\left(Y_{i}-Y_{0}\right)\right]$

Formülde, $N A$ nispi çap ya da boy artımını, $X_{0}$ fidanın dikim anındaki dip çap ya da boyunu, $X_{i} 1 ., 2$. ve 3. yıllardaki çap ya da boylarını, $Y_{0}$ dikim anındaki yaşını, $Y_{i}$ ise 1., 2. ve 3. yıllardaki yaşları ifade etmektedir.

Farklı sıklık derecelerinde yetiştirilen $2+0$ yaşl1 Toros sediri fidanlarının 1., 2. ve 3 . vejetasyon dönemi sonundaki yaşama yüzdeleri, çap ve boy gelişimleri ile nispi çap ve boy artımları arasındaki farklılıklar varyans analizi ve takiben Duncan testi ile denetlenmiştir. Sonuçlar $\alpha=0,05$ düzeyinde istatistiki olarak farklı kabul edilmiştir. İstatistik analizlerde SPSS paket programı kullanılmıştır (SPSS v.22.0 $\left.{ }^{\circledR}, 2015\right)$.

\section{Bulgular}

Farklı sıklık derecelerinde yetiştirilen fidanlar, 1., 2. ve 3. vejetasyon dönemine ait yaşama yüzdeleri bakımından gerek yarı kurak ve yarı nemli deneme alanlarında gerek yarı kurak ve yarı nemli deneme alanları arasında istatistiksel bakımdan anlamlı bir farkl1lık göstermemiştir ( $P>0,05$; Şekil 1).

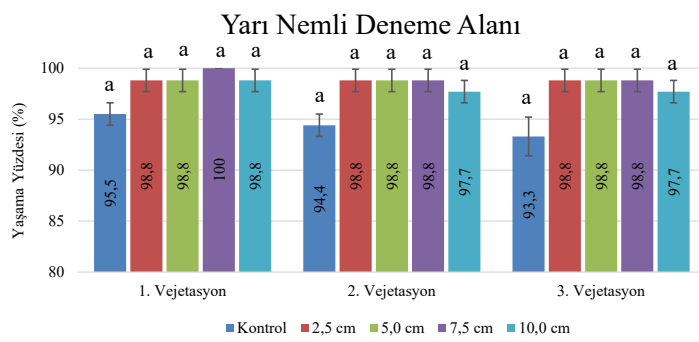

Şekil 1. Farklı sıklık derecelerinde yetiştirilen Toros sediri fidanlarının deneme alanlarındaki yaşama yüzdeleri Figure 1. Survival percentages of Taurus cedar seedlings grown at different seedbed densities in trial areas

Yarı kurak iklim özelliklerine sahip olan Sazak deneme alanında, farklı sıklıklarda yetiştirilen fidanların 1., 2. ve 3. vejetasyon dönemine ait fidan boyu ve kök boğazı çapı gelişimleri arasındaki farklılıklar önemli bulunmuştur $(P<0,05)$. Genel olarak değerlendirildiğinde, 7,5 ve $10,0 \mathrm{~cm}$ mesafe ile yetiştirilen fidanlar $1 ., 2$. ve 3 . vejetasyon dönemi sonunda en iyi boy gelişimi gösterirken, kontrol 
ve 2,5 cm mesafe ile yetiştirilen fidanlar boy bak1mından en zayıf gelişimi göstermiştir. Her üç vejetasyon döneminde de en iyi çap gelişimi yine 7,5 ve $10,0 \mathrm{~cm}$ mesafe ile yetiştirilen fidanlarda elde edilirken, en zayıf çap gelişimi kontrol fidanlarında elde edilmiştir (Tablo 2).

1., 2. ve 3. vejetasyon dönemi sonundaki nispi çap ve boy artımı bakımından yetiştirme sıklıkları arasındaki farklılıklar istatistiksel bakımdan önemli bulunmuş $(P<0,05)$ olup, kontrol fidanları en iyi gelişimi göstermiştir. Kontrol dişındaki sıklık dereceleri nispi boy artımı bakımından benzer bulunurken, en düşük nispi çap artımı 10,0 cm mesafe ile yetiştirilen fidanlarda elde edilmiştir (Tablo 2).

Tablo 2. Yarı kurak deneme alanında, farklı sıklık derecelerinde yetiştirilen Toros sediri fidanlarının, vejetasyon dönemlerine göre çap ve boy gelişimleri ile nispi artımları

Table 2. Diameter, height growth and relative increments of Taurus cedar seedlings grown at different seedbed densities in the semi-arid trial area in relation to the vegetation periods

\begin{tabular}{|c|c|c|c|c|c|c|c|c|}
\hline \multirow[b]{2}{*}{$\begin{array}{l}\text { Vejetasyon } \\
\text { dönemi }\end{array}$} & \multirow[b]{2}{*}{ Özellikler } & \multicolumn{5}{|c|}{ İşlemler (mesafe) } & \multirow[b]{2}{*}{$\mathrm{F}$} & \multirow[b]{2}{*}{$P$} \\
\hline & & $\begin{array}{c}\text { I (Kontrol) } \\
\bar{X} \pm \mathrm{SH}\end{array}$ & $\begin{array}{c}\mathrm{II}(2,5 \mathrm{~cm}) \\
\bar{X} \pm \mathrm{SH}\end{array}$ & $\begin{array}{c}\mathrm{III}(5,0 \mathrm{~cm}) \\
\bar{X} \pm \mathrm{SH}\end{array}$ & $\begin{array}{c}\mathrm{IV}(7,5 \mathrm{~cm}) \\
\bar{X} \pm \mathrm{SH}\end{array}$ & 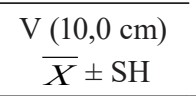 & & \\
\hline \multirow{2}{*}{$\begin{array}{l}\text { Dikim } \\
\text { (2017 İB) }\end{array}$} & FB & $19,2 \pm 0,59$ & $21,5 \pm 0,45$ & $24,7 \pm 0,58$ & $25,4 \pm 0,46$ & $25,2 \pm 0,55$ & & \\
\hline & KBÇ & $3,56 \pm 0,09$ & $4,45 \pm 0,10$ & $5,31 \pm 0,11$ & $5,44 \pm 0,12$ & $5,81 \pm 0,11$ & & \\
\hline \multirow{4}{*}{$\begin{array}{c}1 \\
(2017 \mathrm{SB})\end{array}$} & FB & $27,2 \pm 0,7 \mathrm{a}$ & $27,8 \pm 0,5 \mathrm{a}$ & $31,1 \pm 0,6 \mathrm{~b}$ & $32,3 \pm 0,6 \mathrm{~b}$ & $31,3 \pm 0,6 b$ & 13,559 & 0,000 \\
\hline & $\mathrm{KBÇ}$ & $5,57 \pm 0,13$ a & $6,19 \pm 0,13 \mathrm{~b}$ & $7,10 \pm 0,14 \mathrm{c}$ & $7,63 \pm 0,14 \mathrm{~d}$ & $7,59 \pm 1,21 \mathrm{~d}$ & 46,336 & 0,000 \\
\hline & NBA & $0,44 \pm 0,03 \mathrm{~b}$ & $0,31 \pm 0,02 \mathrm{a}$ & $0,27 \pm 0,02 \mathrm{a}$ & $0,28 \pm 0,02 \mathrm{a}$ & $0,26 \pm 0,02 \mathrm{a}$ & 13,938 & 0,000 \\
\hline & NÇA & $0,61 \pm 0,05 \mathrm{c}$ & $0,41 \pm 0,03 \mathrm{~b}$ & $0,35 \pm 0,02 \mathrm{ab}$ & $0,42 \pm 0,02 \mathrm{~b}$ & $0,32 \pm 0,02 \mathrm{a}$ & 15,450 & 0,000 \\
\hline \multirow{4}{*}{$\begin{array}{c}2 \\
(2018 \mathrm{SB})\end{array}$} & FB & $44,1 \pm 1,3$ a & $44,4 \pm 1,1 \mathrm{a}$ & $47,9 \pm 1,2 \mathrm{~b}$ & $52,3 \pm 1,2 \mathrm{c}$ & $48,8 \pm 1,2 \mathrm{~b}$ & 8,154 & 0,000 \\
\hline & $\mathrm{KBÇ}$ & $9,86 \pm 0,24 \mathrm{a}$ & $10,71 \pm 0,26 \mathrm{~b}$ & $11,26 \pm 0,27 \mathrm{~b}$ & $12,66 \pm 0,25 \mathrm{c}$ & $12,05 \pm 0,25 \mathrm{c}$ & 18,743 & 0,000 \\
\hline & NBA & $0,69 \pm 0,04 \mathrm{~b}$ & $0,56 \pm 0,03$ a & $0,50 \pm 0,03 \mathrm{a}$ & $0,55 \pm 0,03$ a & $0,50 \pm 0,03 \mathrm{a}$ & 5,894 & 0,000 \\
\hline & NÇA & $0,93 \pm 0,05 \mathrm{c}$ & $0,73 \pm 0,03 \mathrm{~b}$ & $0,58 \pm 0,03 \mathrm{a}$ & $0,70 \pm 0,03 \mathrm{~b}$ & $0,55 \pm 0,02 \mathrm{a}$ & 21,063 & 0,000 \\
\hline \multirow{4}{*}{$\begin{array}{c}3 \\
(2019 \mathrm{SB})\end{array}$} & FB & $58,3 \pm 1,6$ a & $61,9 \pm 1,6 \mathrm{ab}$ & $65,5 \pm 1,8 \mathrm{bc}$ & $68,5 \pm 1,4 \mathrm{c}$ & $66,8 \pm 1,6 \mathrm{c}$ & 6,453 & 0,000 \\
\hline & $\mathrm{KBÇ}$ & $14,54 \pm 0,40 \mathrm{a}$ & $16,31 \pm 0,44 \mathrm{~b}$ & $16,73 \pm 0,44 \mathrm{bc}$ & $18,26 \pm 0,37 \mathrm{~d}$ & $17,56 \pm 0,36 \mathrm{~cd}$ & 12,559 & 0,000 \\
\hline & NBA & $0,72 \pm 0,04 \mathrm{~b}$ & $0,65 \pm 0,03 \mathrm{ab}$ & $0,59 \pm 0,03 \mathrm{a}$ & $0,59 \pm 0,02 \mathrm{a}$ & $0,58 \pm 0,03 \mathrm{a}$ & 4,192 & 0,002 \\
\hline & NÇA & $1,08 \pm 0,05 \mathrm{~d}$ & $0,92 \pm 0,04 \mathrm{c}$ & $0,75 \pm 0,03 \mathrm{ab}$ & $0,82 \pm 0,03 \mathrm{bc}$ & $0,69 \pm 0,02 \mathrm{a}$ & 17,369 & 0,000 \\
\hline
\end{tabular}

$\bar{X}$ : aritmetik ortalama, SH: standart hata, F: varyans oranı, $P$ : önem düzeyi, FB: fidan boyu (cm), KBC: kök boğazı çapı (mm), NBA: nispi boy artımı, NÇA: nispi çap artımı, İB: ilkbahar, SB: sonbahar, satırlardaki aynı harfler aralarında fark bulunmayan benzer grupları göstermektedir.

Fidanlıkta farklı sıklık derecelerinde yetiştirilen $2+0$ yaşlı Toros sediri fidanlarının dikim şokunu atlatma süreleri Tablo 3'de verilmiştir. Dikim şoku, çap gelişimi bakımından kontrol, 2,5 ve 7,5 $\mathrm{cm}$ mesafe ile yetiştirilen fidanlarda bir yıl; 5,0 ve $10,0 \mathrm{~cm}$ mesafe ile yetiştirilen fidanlarda iki yıl devam etmektedir. Boy gelişimi bakımından ise 5,0 $\mathrm{cm}$ mesafe ile yetiştirilen fidanlarda iki yıl, diğer sıklıklarda yetiştirilen fidanlarda bir yıl devam etmiştir.

\section{Tartışma ve Sonuç}

Farklı s1klık derecelerinde yetiştirilen Toros sediri fidanlarının, 1., 2. ve 3. vejetasyon dönemine ait yaşama yüzdeleri bakımından, yarı kurak ve yarı nemli deneme alanları arasında önemli bir farkl1lık göstermemesi, deneme alanlarının iklim tipleri yanında toprak özelliklerinin yarı kurak sahada orta tekstürlü, yarı nemli sahada ise ince tekstürlü olmasından kaynaklandığ düşünülmektedir. Yine fidanların 1. vejetasyon dönemine ait tutma başarisı bakımından deneme alanları arasındaki farkın önemsiz bulunması, özellikle yarı kurak alandaki 2017 y1lı yaz (haziran + temmuz + ağustos) yağ1şlarının (101 mm), uzun yıllar ortalaması (19902020) yaz yağışlarının (63 mm) üzerinde olması (MGM, 2021) ile açıklanabilir.

Farklı sıklıkta yetiştirilen fidanların yarı kurak ve yar1 nemli alanlardaki 1., 2. ve 3. vejetasyon dönemine ait yaşama yüzdeleri arasında önemli bir farklılık ortaya çıkmamıştır. Keza, Güner ve ark. $(2008,2012)$ tarafindan Anadolu karaçamında yapılan çalışmalarda, yetiştirme sıklığının, 1 ., 3., 5. ve 8. vejetasyon dönemi sonundaki yaşama yüzdesi üzerinde anlamlı bir etkisinin bulunmad1$\breve{g} 1$ bildirilmektedir. Yine yalanc1 akasya (Robinia pseudoacacia L.) (Semerci ve ark., 2008), doğu ladini (Picea orientalis (L.) Link) (Eyüboğlu, 1988) ve sivri meyveli dişbudak (Fraxinus angustifolis Vahl.) (Çiçek ve ark., 2007) türlerinde yapılan çalış- 
Tablo 3. Yarı kurak deneme alanında, fidanların nispi çap ve boy artımları esas alınarak gerçekleştirilen varyans analizi ve Duncan testi sonuçları

Table 3. Variance analysis and Duncan test results based on the relative diameter and height increases of the seedlings in the semi-arid trial area

\begin{tabular}{|c|c|c|c|c|c|c|c|c|c|c|c|c|c|}
\hline \multirow{2}{*}{ İşlemler } & \multirow{2}{*}{$\begin{array}{c}\text { Nispi çap } \\
\text { Artımı }\end{array}$} & \multicolumn{7}{|c|}{ Homojen gruplar } & \multirow{2}{*}{$\begin{array}{l}\text { Nispi boy } \\
\text { artımı }\end{array}$} & \multicolumn{4}{|c|}{ Homojen gruplar } \\
\hline & & 1 & 2 & 3 & 4 & 5 & 6 & 7 & & 1 & 2 & 3 & 4 \\
\hline Kontrol (1. y1l) & 0,613 & & & $\mathrm{c}$ & $\mathrm{d}$ & $\mathrm{e}$ & & & 0,442 & $\mathrm{a}$ & $b$ & $\mathrm{c}$ & \\
\hline Kontrol (2. y1l) & 0,923 & & & & & & $\mathrm{f}$ & g & 0,693 & & & & $\mathrm{~d}$ \\
\hline Kontrol (3. y11) & 1,090 & & & & & & & g & 0,727 & & & & $\mathrm{~d}$ \\
\hline $2,5 \mathrm{~cm}(1 . \mathrm{y} 1 \mathrm{l})$ & 0,404 & $\mathrm{a}$ & $\mathrm{b}$ & $\mathrm{c}$ & & & & & 0,309 & $\mathrm{a}$ & b & & \\
\hline $2,5 \mathrm{~cm}(2 . \mathrm{y} 1 \mathrm{l})$ & 0,724 & & & & $\mathrm{~d}$ & $\mathrm{e}$ & $\mathrm{f}$ & & 0,554 & & & $\mathrm{c}$ & $\mathrm{d}$ \\
\hline $2,5 \mathrm{~cm}(3 . \mathrm{y} 1 \mathrm{l})$ & 0,915 & & & & & & $\mathrm{f}$ & g & 0,649 & & & $\mathrm{c}$ & $\mathrm{d}$ \\
\hline $5,0 \mathrm{~cm}(1 . \mathrm{y} 1 \mathrm{l})$ & 0,353 & $\mathrm{a}$ & $\mathrm{b}$ & & & & & & 0,272 & $\mathrm{a}$ & $\mathrm{b}$ & & \\
\hline $5,0 \mathrm{~cm}(2 . \mathrm{y} 1 \mathrm{l})$ & 0,577 & & $\mathrm{~b}$ & $\mathrm{c}$ & $\mathrm{d}$ & $\mathrm{e}$ & & & 0,498 & & b & $\mathrm{c}$ & $\mathrm{d}$ \\
\hline $5,0 \mathrm{~cm}$ (3. y1l) & 0,744 & & & & $\mathrm{~d}$ & $\mathrm{e}$ & $\mathrm{f}$ & & 0,582 & & & $\mathrm{c}$ & $\mathrm{d}$ \\
\hline $7,5 \mathrm{~cm}$ (1. y1l) & 0,424 & $\mathrm{a}$ & $\mathrm{b}$ & $\mathrm{c}$ & & & & & 0,279 & $\mathrm{a}$ & $\mathrm{b}$ & & \\
\hline $7,5 \mathrm{~cm}(2 . \mathrm{y} 1 \mathrm{l})$ & 0,694 & & & & d & e & $\mathrm{f}$ & & 0,548 & & & $\mathrm{c}$ & $\mathrm{d}$ \\
\hline 7,5 cm (3. y1l) & 0,819 & & & & & $\mathrm{e}$ & $\mathrm{f}$ & & 0,585 & & & $\mathrm{c}$ & $\mathrm{d}$ \\
\hline $10,0 \mathrm{~cm}(1 . \mathrm{y} 1 \mathrm{l})$ & 0,319 & $\mathrm{a}$ & & & & & & & 0,260 & $\mathrm{a}$ & & & \\
\hline $10,0 \mathrm{~cm}(2 . \mathrm{y} 1 \mathrm{l})$ & 0,554 & $\mathrm{a}$ & $\mathrm{b}$ & $\mathrm{c}$ & $\mathrm{d}$ & & & & 0,496 & & b & $\mathrm{c}$ & $\mathrm{d}$ \\
\hline $10,0 \mathrm{~cm}(3 . \mathrm{y} 11)$ & 0,693 & & & & $\mathrm{~d}$ & $\mathrm{e}$ & $\mathrm{f}$ & & 0,575 & & & $\mathrm{c}$ & $\mathrm{d}$ \\
\hline $\mathrm{F}$ & & & & & $8,89^{\prime}$ & & & & & & & & \\
\hline$P$ & & & & & 0,00 & & & & & & & & \\
\hline
\end{tabular}

malarda da, yetiştirme sıklı̆̆ının arazideki yaşama yüzdesi üzerinde önemli bir etkisinin bulunmadığ 1 belirlenmiştir. Ancak, Tetik (1995) tarafından sarıçam (Pinus sylvestris L.)'da yapılan çalışmada, yetiştirme sıklığının yaşama yüzdesi üzerinde etkili olduğu belirtilmiştir. Genel olarak seyrek yetiştirilen fidanların arazideki yaşama yüzdeleri, sık yetiştirilenlere göre daha fazladır. Ancak, yaşama yüzdesinin yüksek olduğu alanlarda, yetiştirme sıklığının yaşama yüzdesi üzerindeki etkisi azalmaktadır (South, 2000). Nitekim çalışmamızda da her işleme ait yaşama yüzdesi \%90'ın üzerinde olup, yetiştirme sıklı̆̆ının yaşama yüzdesi üzerindeki etkisi kaybolmuştur.

1., 2. ve 3. vejetasyon dönemi sonundaki fidan boyu ve kök boğazı çapı gelişimi bakımından yetiştirme sıklıkları arasındaki farklılıklar önemli bulunmuştur. Genel olarak, 1., 2. ve 3. vejetasyon dönemi sonundaki boy ve çap gelişimi bakımından 7,5 ve $10,0 \mathrm{~cm}$ mesafe ile yetiştirilen fidanlar en iyi gelişimi gösterirken, kontrol fidanları en zayıf gelişimi göstermiştir. Dolayısıyla, seyrek yetiştirilen fidanların, sık yetiştirilen fidanlara göre denemenin başlangıcında sahip olduğu çap ve boy (dikim boyu ve çapı) avantajı (Tablo 2) 3. vejetasyon dönemi sonu itibariyle devam etmiştir. Anadolu karaçamı (Güner ve ark., 2008) ve yalancı akasya
(Semerci ve ark., 2008) türlerinde yapılan çalıșmalarda da benzer sonuçlara ulaşılmıştır. Ancak, farklı sıklık derecelerinde yetiştirilen fidanlarının 1., 2. ve 3. vejetasyon dönemi sonundaki nispi çap ve boy artımı değerlerine baktığımızda, kontrol fidanlarının en iyi gelişimi gösterdiği görülmektedir. Yani kısa boylu ve ince çapılı fidanların nispi gelişimi daha iyidir. Bu durum, birçok çalışmada ortaya koyulmuş ve zaten beklenen bir olgudur. Çünkü küçük boyutlu fidanlar dikim şokundan daha az etkilenmektedir (Dirik, 1990). Her ne kadar 3. vejetasyon dönemi sonu itibariyle 7,5 ve 10,0 $\mathrm{cm}$ mesafe ile yetiştirilen fidanlar diğger sıklıklarda yetiştirilen fidanlara göre 5-6 $\mathrm{cm}$ daha boylu olsa da nispi artımlara bakıldığında ileriki dönemde bu farklılı̆̆ın kapanması mümkün görünmektedir. Nitekim, Çiçek ve ark. (2011), sivri meyveli dişbudak ve hercai karaağaç (Ulmus leavis Pall.) fidanlarında yaptıkları çalışmada, fidanlık aşamasında yetiştirme sıklığının çap ve boy gelişimi üzerinde etkili olduğunu, ancak arazide 4. vejetasyon dönemi sonunda boy farklılıklarının devam etmesine rağmen önemli düzeyde olmadığını bildirmektedir. Güney Florida çamı (Pinus elliottii Engelm.) türünde yapılan çalışmada, fidanlıkta üç boy grubuna ayrılarak araziye taşınan fidanlar arasındaki boy farkının, 3. vejetasyon dönemi sonunda devam etmesine rağmen, 10. yıldan itibaren ortadan kalk- 
tığı bildirilmektedir (Sluder, 1991).

Yarı kurak deneme alanındaki dikim şoku, çap gelişimi bakımından 5,0 ve 10,0 cm mesafe ile yetiştirilen fidanlarda iki yıl, kontrol, 2,5 ve $7,5 \mathrm{~cm}$ mesafe ile yetiştirilen fidanlarda bir yıl devam etmiştir. Boy gelişimi bakımından 5,0 cm mesafe ile yetiştirilen fidanlarda iki yıl, diğer sıklıklarda yetiştirilen fidanlarda ise bir yıl sürmüştür. Anadolu karaçamında, farklı sıklıkta yetiştirilen fidanların dikim şokunu atlatma süresinin bir yıl olduğu bildirilmektedir (Güner ve ark., 2008). Dikim şokunun boylu ve daha kalın çaplı olan $10 \mathrm{~cm}$ mesafe ile yetiştirilen fidanlarda daha uzun süre devam etmesi, fidanlıkta söküm veya arazide dikim sırasında büyük fidanların daha fazla zarar görmesinden veya daha geniş transpirasyon yüzeyleri sebebiyle daha fazla su kaybına maruz kalmalarından kaynaklanabilir (Dirik, 1990).

Elde edilen bulgular bir arada değerlendirildiğinde, farklı sıklıkta yetiştirilen fidanlar, plantasyon denemelerinde yaşama yüzdeleri bakımından anlamlı bir farklılık göstermemiştir. Fidan boyu ve kök boğazı çapı gelişimi bakımından genel olarak 7,5 ve $10,0 \mathrm{~cm}$ mesafe ile yetiştirilen fidanlar en iyi, kontrol fidanları ise en zayıf gelişimi göstermiştir. Nisbi çap ve boy artımı bakımından ise kontrol fidanları en iyi gelişimi göstermiştir. Dikim şoku genel olarak kontrol, 2,5 ve 7,5 cm mesafe ile yetiştirilen fidanlarda $1 \mathrm{y} 1 \mathrm{l}, 5,0$ ve $10,0 \mathrm{~cm}$ mesafe ile yetiştirilen fidanlarda 2 yıl devam etmiştir. Buna göre 2,5 ve 7,5 cm mesafe ile yetiştirilen fidanların ön plana çıktığ 1 görülmektedir. Bu fidanlardan 2,5 $\mathrm{cm}$ mesafe ile yetiştirilen fidanların dikim sırasındaki gövde/kök oranı en düşük bulunmuştur (Güner ve ark., 2018). Dolayısıyla, fidanlıklarda birim alandan dikime elverişli fazla sayıda fidan üretme gerekliliği de dikkate alındığında, yarı kurak alan ağaçlandırmalarında, fidanlıkta 2,5 cm mesafe ile yetiştirilen (232 fidan $/ \mathrm{m}^{2}$ ) fidanların kullanılmasının uygun olacağı söylenebilir.

\section{Teşekkür}

Bu makale, Orman Genel Müdürlüğü, Orman Toprak ve Ekoloji Araştırmaları Enstitüsü Müdürlüğü’nce desteklenen "Toros Sediri (Cedrus libani A. Rich.)'nde Yetiştirme Sıklığının Önemli Morfolojik Fidan Özellikleri, Beslenme Durumu ve Arazi Başarısına Etkisi (ESK-24(1202)/2015-2020)" isimli projeden hazırlanmıştır. Makaleye yaptıkları çok değerli katkılar sebebiyle hakemlere teşekkür ederiz.

\section{Kaynaklar}

Alım, E., Kavgac1, A., 2017. Eğirdir Orman Fidanl1ğı'nda diken ardıcı (Juniperus oxycedrus L. subsp. oxycedrus) fidan yetiştirme sıklığının fidan morfolojisine etkileri. Ormancılık Araştırma Dergisi 4(2): 1-11. https://doi.org/10.17568/ogmoad.309242

Boydak, M., Çalıkoğlu, M., 2008. Toros Sedirinin (Cedrus libani A. Rich.) Biyolojisi ve Silvikültürü. Ormancılığı Geliştirme ve Orman Yangınları ile Mücadele Hizmetlerini Destekleme Vakfı (OgemVak) Yayını, Ankara.

Çatal, A.Y., 2002. Toros Sediri (Cedrus libani A. Rich.)'nde Yetiştirme Sıklığının Bazı Morfolojik Fidan Özelliklerine Etkisi. Süleyman Demirel Üniversitesi, Fen Bilimleri Enstitüsü, Yüksek Lisans Tezi, Isparta.

ÇEM, 2015. Çölleşme ve Erozyonla Mücadele Genel Müdürlüğü, Ormancılık İstatistikleri. http:// www.cem.gov.tr/erozyon/AnaSayfa/istatistikler. aspx?sflang=tr (Ziyaret tarihi: 06.04.2015).

Çiçek, E., Çiçek, N., Bilir, N., 2007. Effects of seedbed density on one-year-old Fraxinus angustifolia seedling characteristics and outplanting performance. New Forests 33: 81-91.

Çiçek, E., Çiçek, N., Tilki, F., 2011. Four-year field performance of Fraxinus angustifolia Vahl. and Ulmus leavis Pall. seedlings grown at different nursery seedbed densities. Research Journal of Forestry 5(2): 89-98.

Deligöz, A., 2012. Ekim sıklı̆̆ının Acer negundo L. fidanlarının morfolojik ve fizyolojik özellikleri üzerine etkisi. Bartın Orman Fakültesi Dergisi 14(21): 11-17.

Dirik, H., 1990. Dikim şoku. İstanbul Üniversitesi Orman Fakültesi Dergisi B40(3): 105-116.

Eyüboğlu, A.K., 1988. Fidanlıkta Değişik Sıklık Derecelerinde Yetiştirilmiş, Şaşırtılmış ve Şaşırtılmamış Doğu Ladini (Picea orientalis (L.) Link) Fidanlarının Arazideki Durumları. Ormanc1lık Araştırma Enstitüsü Yayınları, Teknik Bülten No: 201, Ankara.

Güner, Ş.T., Çömez, A., Karataş, R., Genç, M., 2008. Anadolu Karaçamı (Pinus nigra Arnold. ssp. pallasiana (Lamb.) Holmboe)'nda Yetiştirme Sıkl1ğının Bazı Morfolojik ve Fizyolojik Fidan Özellikleri ile Dikim Başarısına Etkisi. Orman Toprak ve Ekoloji Araştırmaları Enstitüsü Müdürlüğü Yayını, Çeşitli Yayınlar Serisi No: 1, Eskişehir.

Güner, Ş.T., Çömez, A., Karataş, R., Genç, M., 2012. Yetiştirme sıklığının Anadolu karaçamı fidanlarının dikim başarısına etkisi. Ístanbul Üni- 
versitesi Orman Fakültesi Dergisi 62(2): 89-96.

Güner, Ş.T., Şahin, U., Güner, D., Karataş, R., Erkan, N., 2016. Effects of seedbed density on some morphological properties and nutrient status of two-year old Taurus cedar (Cedrus libani A. Rich.) seedlings. Fresenius Environmental Bulletin 25(6): 2121-2130.

Güner, Ş.T., Güner, D., Şahin, U., 2018. Toros sedirinde yetiştirme sıklığının fidan morfolojik özellikleri ve beslenme durumuna etkisi. Ormancılık Araştırma Dergisi 5(1): 44-55. https://doi. org/10.17568/ogmoad.357442

Kayadibi, B., 2011. Toros Sedirinin Fidanlıkta Yetiştirilmesinde Seyreltme ve Kök Kesimi İşlemlerinin Etkisi. Artvin Çoruh Üniversitesi, Fen Bilimleri Enstitüsü, Yüksek Lisans Tezi, Artvin.

MGM, 2021. Meteoroloji Genel Müdürlüğü, Eskişehir ili meteorolojik verileri, Ankara.

Özyuvacı, N., 1999. Meteoroloji ve Klimatoloji, İstanbul Üniversitesi Orman Fakültesi Yayınları, İstanbul.

Semerci, A., Güner, Ş.T., Çömez, A., Çelik, N., Karataş, R., Koray, E. Ş., Genç, M., Tuncer, E., Güner, D., 2008. Yetiştirme Sıklığının Yalancı Akasya (Robinia pseudoacacia L.) Fidanlarının Bazı Morfolojik ve Fizyolojik Özellikleri ile Dikim Başarısına Etkileri: Eskişehir Örneği. İç Anadolu Ormancılık Araştırma Enstitüsü Yayınları, Teknik Bülten No: 285, Ankara.

Sluder, E.L., 1991. Seed and seedling size grading of slash pine has little effect on long-term growth of trees. Tree Planters' Notes 42(3): 23-27.

South, D.B., 2000. Planting morphologically improved pine seedlings to increase survival and growth. Auburn University, Alabama Agricultural Experiment Station, Forestry and Wildlife Research Series No. 1, Auburn, Alabama.

SPSS v.22.0®, 2015. SPSS 22.0 Guide to Data Analysis. published by Prentice Hall, Upper Saddle River, New Jersey, USA.

Tetik, M., 1995. Sarıkamış Fidanlığında Ekim Sıklığının Sarıçam (Pinus sylvestris L.) Fidanlarının Kalitesine ve Dikimdeki Başarısına Etkileri. Ormancılık Araştırma Enstitüsü Yayınları, Teknik Bülten No: 244, Ankara.

Tolay, U., 1983. Hendek Orman Fidanlığında Uludağ Göknarı (Abies bornmülleriana Mattf.)'nın Yetiştirme Tekniği ile Fidan Kalitesi ve Dikim Başarısı Arasındaki İlişkiler Üzerine Araştırmalar. Kavak ve Hızlı Gelişen Yabancı Tür Orman Ağaçları Araştırma Enstitüsü Yayınları, Yıllık Bülten No: 19, 349-448.

Yahyaoğlu, Z., Genç, M., 2007. Fidan Standardizasyonu, Standart Fidan Yetiştirmenin Biyolojik ve Teknik Esasları. Süleyman Demirel Üniversitesi, Orman Fakültesi Yayınları, Isparta.

Yücedağ, C., Gailing, O., 2012. Effects of seedbed density on seedling morphological characteristics of four broadleaved species. Forest Systems 21(2): 218-222. 